引用格式: 许朗, 陈杰, 刘晨. 小农户与新型农业经营主体的灌溉用水效率及其影响因素比较 [J]. 资源科学, 2021, 43(9): 18211833. [Xu L, Chen J, Liu C. Comparison of irrigation efficiency of smallholder farmers and new agricultural operators and influencing factors[J]. Resources Science, 2021, 43(9): 1821-1833.] DOI: 10.18402/resci.2021.09.09

\title{
小农户与新型农业经营主体的灌溉用水效率 及其影响因素比较
}

\author{
许 朗, 陈 杰, 刘 晨
}

(南京农业大学经济管理学院, 南京 210095)

\begin{abstract}
摘 要: 基于对黄淮海平原 2017 年的实地调研数据,选取冬小麦作为研究对象,应用随机前沿模型对小农户和 种粮大户、家庭农场与农民专业合作社 3 类新型农业经营主体冬小麦的农业灌溉用水效率进行测算, 并运用 Tobit 模型探究影响不同农业经营主体农业灌溉用水效率的因素。研究发现: 1)小农户、种粮大户、家庭农场和农民专业 合作社样本中农业灌溉用水效率值的差异较大。家庭农场和农民专业合作社的农业灌溉用水效率值集中在 $70 \%$ 以上的水平,而小农户集中在 $10 \%$ 30\%的水平; (2)结合各个农业经营主体的技术效率可知,小农户和新型农业经营 主体的农业灌溉用水效率均有一定的提高空间; (3)小农户和新型农业经营主体在农业灌溉用水效率的影响因素方 面有显著的不同,农业收入占比、用水成本和是否采用灌溉技术等因素对所有农业经营主体的农业灌溉用水效率 都会有正向影响。在新型农业经营主体中,农户的年龄、灌溉面积、灌溉设施等因素能够影响其农业灌溉用水效 率, 但是对于小农户的农业灌溉用水效率无显著的影响。小农户是促进节水灌溉技术应用和提高农业灌溉用水 效率的重要对象。加快传统农户向新型农业经营主体转型、加大公共服务建设等措施有助于农业灌溉用水效率的 提高。
\end{abstract}

关键词: 小农户; 新型农业经营主体; 灌溉用水效率; 随机前沿模型 (SFA); 黄淮海平原

DOI :10.18402/resci.2021.09.09

\section{1 引言}

农业一直是中国的用水大户。据 2018 年《水资 源公报》统计, 当年的中国农业用水占比 $61.4 \%$, 耕 地实际灌溉亩均用水量 $365 \mathrm{~m}^{3}$, 农田灌溉水有效利 用系数仅为 0.554 , 而多数国家已超 0.700 。每年因 灌溉低效而减少的粮食产量约达 350 亿 $\mathrm{kg}$, 再加上 工业化进程的加快, 进一步挤占了农业用水, 导致 农业灌溉面临巨大的压力 ${ }^{[1]}$ 。因此, 发展节水灌溉 技术, 提高灌溉用水效率, 是减少农业水资源浪费、 缓解农业用水不足的重要举措。中国是世界上农 业水资源严重缺乏的国家之一, 但是由于自然条件 和农户行为习惯等原因的限制, 节水灌溉技术未能
得到充分普及,农户灌溉低效的问题普遍存在 ${ }^{[2,3]}$ 。 与此同时, 中国农业生产主体已由传统的小农户逐 步发展为更为丰富的新型农业经营主体 ${ }^{[4,5]}$ 。自 2012 年新型农业经营主体概念被正式提出后, 之后 每年的农村会议文件中都不断强调要努力培育和 发展新型农业经营主体。作为未来农业生产的主 力, 新型农业经营主体将对提高中国农业灌溉用水 效率作出重要影响 ${ }^{[6,7]}$ 。因此, 通过比较传统小农户 和新型农业经营主体在农业灌溉用水效率上的差 异, 能够体现两者在灌溉用水行为和节水灌溉技术 应用上的异质性, 为提高中国农业经营主体的灌溉 用水效率提出针对性建议,进而缓解中国水资源不

收稿日期: 2020-03-23, 修订日期: 2020-10-18

基金项目: 国家自然科学基金项目(71973065;71573126)。

作者简介: 许朗, 男, 江苏南京人, 教授, 主要从事农业经济管理研究。E-mail: xulang@njau.edu.cn

通讯作者: 刘晨, 女, 安徽淮南人, 硕士, 主要从事技术经济管理研究。E-mail: liu_chvip@126.com 
足的现状。

很多文献围绕中国农业灌溉用水效率的测算 和影响因素进行了研究。根据已有文献, 农业灌溉 用水效率是指在既定产出和要素投人下, 达到技术 充分有效且无效率损失时的最小灌溉用水量与实 际用水量之比 ${ }^{[8,9]}$ 。农业灌溉用水效率常见的计算 方法有数据包络法 (DEA) 和随机前沿模型法 (SFA)。孙才志等 ${ }^{[10]}$ 应用 DEA 计算了中国 19972007 连续 11 年 31 个省的水资源利用相对效率, 表 明了中国省级行政区域间农业灌溉用水效率有显 著差异。相对于 DEA 法, 由于 SFA 法能够揭示其中 的影响机制, 因此被更多的学者所采用 ${ }^{[11-13]}$ 。王晓 娟等 ${ }^{[14]}$ 选取 SFA 方法, 测算了河北省石津灌区的农 业灌溉用水效率和影响因素, 结果发现该灌区的农 业灌溉用水效率为 0.75 。王学洲等 ${ }^{[15]}$ 选取了 31 个 省级面板数据, 利用 SFA 方法测算发现, 中国的平 均农业灌溉用水效率仅为 0.49 , 且地区差异较大,西 北地区节水潜力较大。王学渊 ${ }^{[16]}$ 还利用省级面板数 据, 对比了 SFA 和 DEA 方法测算出的农业灌溉用水 效率, 发现两种方法测算出的农业灌溉用水效率排 名具有一致性, 且南方省份和直辖市的农业灌溉用 水效率较高, 西北地区的农业灌溉用水效率最低。 有关农业灌溉用水效率影响因素的研究发现, 节水 灌溉技术、农业水价以及农民用水协会均能影响农 业灌溉用水效率, 但是节水灌溉技术应用对农业灌 溉用水效率的提高作用最为显著 ${ }^{[17,18]}$ 。在各种节水 灌溉技术中, 滴灌的用水效率通常是最高, 只有在 特定的地理环境和作物生长特征下, 滴灌的用水效 率才会有所下降 ${ }^{[19,20]}$ 。但是作为未来中国农业的主 力军, 新型农业经营主体的农业灌溉用水效率却受 到关注较少。张义珍 ${ }^{[21]}$ 认为农业经营主体是指这样 一群个人和组织, 即直接或间接进行农产品的生 产、销售和服务等工作。陈晓华 ${ }^{[22]}$ 和李宁等 ${ }^{[23]}$ 学者 认为新型农业经营主体是区别于小农户的, 规模 化、组织化、集约化、社会化和现代化的农业经营主 体。这种解释得到很多学者的认可 ${ }^{[24]}$ 。本文也将延 用这种对新型农业经营主体的核心内涵解释,将新 型农业经营主体定义为: 以商品化经营为目标, 从 事规模化经营, 具备先进生产条件和先进管理水平 的农业经营组织,具体包括家庭农场、种粮大户、农
民专业合作社和龙头企业等。龙头企业所经营的 内容涵盖整个产业链条, 除农产品种植外, 农产品 加工、仓储、物流运输、销售甚至科研占据了其经营 中很重要的部分。由于本文所分析的问题主要是 针对农产品种植以及龙头企业相关数据获取的困 难性,所以本文的新型农业经营主体不包括龙头 企业。

综上可知,尽管有关农业灌溉用水效率的文献 较为丰富,但是基于不同农业经营主体间的生产特 征差异的事实,对不同农业经营主体间农业灌溉用 水效率的比较分析仍旧缺乏, 这将成为本文的主要 研究内容。具体而言, 本文将采用随机前沿模型测 算小农户和新型农业经营主体的农业灌溉用水效 率,并重点比较分析两者间农业灌溉用水效率的差 异和受到的影响因素的异同。

\section{2 数据来源、模型方法和变量选择}

\section{1 数据来源与调研区域}

\subsection{1 数据来源}

本文的研究内容是对小农户和新型农业经营 主体的农业灌溉用水效率及其影响因素进行对比 分析,选取黄淮海平原冬小麦作为研究对象,所用 数据是基于作者及课题组成员于 2017 年 3 月至 7 月 期间对黄淮海平原农户小麦生产灌溉用水情况进 行的调研, 以及于 2018 年 5 月至 7 月进行的补充调 研。本文主要采取随机抽样法对农户进行问卷调 查,首先根据各个省份的县级行政单位数量进行等 比例抽样, 然后根据各个县的村集体数量进行同样 的等比例抽样, 最后根据各个村集体的人口数量进 行等比例随机抽样。在对农业生产经营主体进行 调查的同时,对相关政府基层人员、村干部进行深 人访谈。调研样本包括山东省 10 个县、安徽省 6 个 县、河南省 7 个县、河北省 6 个县、江苏省 3 个县。根 据抽样结果,调研期间向小农户、种粮大户、家庭农 场以及农民专业合作社负责人共发放问卷 960 份, 回收有效问卷 875 份, 问卷有效回收率为 $91.15 \%$ 。 为了提高小农户和新型农业经营主体对比分析结 果的代表性,控制地形地貌和气候变化等因素的影 响,本文剔除了村集体中无新型农业经营主体的农 户样本, 共筛选出 625 份样本用于研究,包括小农户 
211 份, 种粮大户 167 份, 家庭农场 118 份, 农民专业 合作社 129 份。需要说明的是, 本文选取的种粮大 户样本不属于农民专业合作社成员，既是种粮大户 又参加合作社的农业经营主体, 本文归类为农民专 业合作社成员, 不纳人分析样本中。农民专业合作 社是一个合作组织, 其带头人一般为经验较为丰富 或受教育程度较高的管理者。本文对于农民专业 合作社的问卷调研, 是针对农民专业合作社带头人 进行的,年龄等个体变量特征也是指农民专业合作 社带头人的个体特征。表 1 显示了样本的具体分布 情况, 各个农业经营主体中, 山东省的样本量占比 最多, 江苏省最少, 样本集中地区的缺水情况较为 相似,灌溉方式多为机井灌, 灌溉用水量较易统计。

\subsection{2 调研区域}

中国小麦生产主要有 3 个主产区 10 个亚区, 黄 淮海平原冬麦区隶属 10 个亚区之一, 主要包括江苏 省及安徽省北部、河南省中北部, 山西省西南部、山 东省南部以及河北省中南部地区。全区小麦面积 约占全国小麦面积的 $45 \%$, 小麦产量约占全国总产 量的 48\%左右, 小麦作为主要作物约占全区粮食种 植面积的 44\%。该区全年平均降水量为 580 860 $\mathrm{mm}$, 正常年份在小麦生育期内的降水量为 152 $287 \mathrm{~mm}$, 但是整个地区的雨量时空分布不均, 干旱 灾害频发。由于地表水短缺,农田用水多为机井灌 溉, 使得地下水长期超采, 造成地下水漏斗以及地 表愈旱的恶性循环。由此可见, 黄淮海平原灌溉用 水的紧缺形势已成为制约其可持续发展的重要因 素之一。因此要大力发展节水产业, 提高农业灌溉 用水效率, 保障粮食生产安全。

\section{2 模型方法}

(1)随机前沿方法。
根据已有研究,选取改进的随机前沿法,并采 用 C-D 生产函数模型进行农业灌溉用水效率的测 算。首先,对农业生产技术效率进行测算, 设 $Y_{i}$ 为农 户的产出,则随机前沿生产函数表示为:

$$
Y_{i}=f\left(X_{i j}, W_{i}, \beta\right) \exp \left(v_{i}-u_{i}\right)
$$

式中: $X_{i j}$ 为第 $i$ 个农户的第 $j$ 种投人要素 (除灌溉用 水量之外); $W_{i}$ 表示灌溉用水量; $\beta$ 为待估参数; $v_{i}$ 为 随机误差, 且服从独立正态分布, 表示的是农业生 产中无法控制的因素,如气候变化、测量误差等; $u_{i}$ 为管理误差项, 表示效率损失, 且 $u_{i}$ 服从半正态分 布, $v$ 与 $u$ 相互独立, 两者皆独立于 $X$ 。当设定 $u_{i}=0$ 时, 不存在效率损失, 达到充分有效, 此时的有效产 出为:

$$
\hat{Y}_{i}=f\left(X_{i j}, W_{i}, \beta\right) \exp \left(v_{i}\right)
$$

则生产技术效率可表示为:

$$
T E_{i}=Y_{i} / \hat{Y}_{i}=Y_{i} / f\left(X_{i j}, W_{i}, \beta\right) \exp \left(v_{i}\right)=\exp \left(-u_{i}\right)
$$

$T E_{i}$ 即为农户的生产技术效率, 是实际产出与技 术充分有效状态下最大产出的比值。式(3)中,分 子代表着农户的实际产出, 分母代表着由公式(2) 得到的有效产出。为得到 Kopp 所定义的农业灌溉 用水效率估计结果, 需要对随机前沿生产函数的形 式进行提前设定, 本文选取 C-D 生产函数模型, 对 其取对数后公式(1)可表示为:

$$
\ln Y_{i}=\beta_{0}+\beta_{w} \ln W_{i}+\sum_{j} \beta_{j} \ln X_{i j}+\left(v_{i}-u_{i}\right)
$$

式中: $W$ 和 $X$ 分别代表农业生产中投人的灌溉用 水量和其他要素,例如劳动力、化肥和农药等。由 于本文对生产函数模型进行了对数转换, 因此变量 系数 $\beta$ 代表各个变量对因变量的弹性影响,即自变 量变化 $1 \%$, 因变量会变化 $\beta \times 100 \%$ 。具体来说, $\beta_{0}$ 代表着常数项; $\beta_{w}$ 代表着灌溉用水量变量对农业产

表 1 调研样本分布

Table 1 Distribution of the survey samples

\begin{tabular}{clcccc}
\hline \multirow{2}{*}{ 市 } & \multicolumn{1}{c}{ 县(区) } & \multicolumn{3}{c}{ 样本量/份 } \\
\cline { 3 - 6 } & & 小农户 & 种粮大户 & 家庭农场 & 农民专业合作社 \\
\hline 山东省 & 苍山县、临沭县、嘉祥县、鱼台县、桓台县、梁山县、邹城 & 85 & 77 & 68 & 70 \\
& 县、高唐县、武城县、高青县 & & & \\
安徽省 & 萧县、灵璧县、浴阳县、利辛县、砀山县、临泉县 & 37 & 26 & 3 & 16 \\
河南省 & 民权县、淇县、商水县、鹿邑县、新乡县、清丰县、尉氏县 & 31 & 31 & 26 & 23 \\
河北省 & 南和县、临漳县、阜城县、河间市、隆尧县、黄骅市 & 40 & 24 & 19 & 17 \\
江苏省 & 沛县、丰县、宿豫区 & 18 & 9 & 2 & 3 \\
\hline
\end{tabular}


出变量的弹性影响值; $\beta_{j}$ 代表着种子投入变量、化 肥和农药投人变量、机械投人变量和劳动力投人变 量对农业产出变量的弹性影响值。

本文将农业灌溉用水效率定义为在产出和投 人不变的情况下, 可能实现的最小用水量与实际用 水量的比值，基于对技术效率测算的分析，假设一 定条件下可实现的最小灌溉用水量为 $\hat{W}_{i}$, 技术有效 状态下对应的产出为 $\hat{Y}_{i}^{w}$, 则式(4)变为:

$$
\ln \hat{Y}_{i}^{w}=\beta_{0}+\beta_{w} \ln \hat{W}_{i}+\sum_{j} \beta_{j} \ln X_{i j}+v_{i}
$$

设式(4)和式 (5)相等, 联立方程得出农业灌溉 用水效率公式为:

$$
T E W_{i}=\hat{W}_{i} / W_{i}=\exp \left(-u_{i} / \beta_{W}\right)=T E_{i}^{\frac{1}{\phi_{w}}}
$$

式中: $\hat{W}_{i}$ 代表着在当前技术条件下可以实现的最小 灌溉用水量; $T E_{i}$ 代表着当前技术条件下的生产技 术效率值。

(2) Tobit模型。

农业灌溉用水效率的测算结果在 $0 \sim 1$ 之间, 是 一个受限的因变量, 面临着数据截取问题, 普通最 小二乘法不再适用, 否则将会产生有偏估计。本文 利用 Tobit模型, 对不同农业经营主体的农业灌溉用 水效率的影响因素进行分析, 将农业灌溉用水效率 作为因变量, 影响因素作为自变量, 模型如下:

$$
T E W_{i}= \begin{cases}0, & \delta_{0}+\sum \delta_{k} Z_{k}+\xi_{i} \leqslant 0 \\ \delta_{0}+\sum \delta_{k} Z_{k}+\xi_{i}, & \delta_{0}+\sum \delta_{k} Z_{k}+\xi_{i}>0\end{cases}
$$

式中: $T E W_{i}$ 为农业灌溉用水效率; $Z_{k}$ 为自变量即影 响因素; $\delta_{0}$ 为待估常数项; $\delta$ 为待估参数; $\xi$ 为误差 项,服从正态分布。

\section{3 主要变量选取与描述统计}

2.3.1 灌溉用水效率测算的变量选取与描述性分析

由于本文对农业灌溉用水效率的研究是在农 业生产技术效率的基础上进行的, 因此选取每公顷 平均产量 $\left(\mathrm{kg} / \mathrm{hm}^{2}\right)$ 作为产出变量, 投人变量包括种

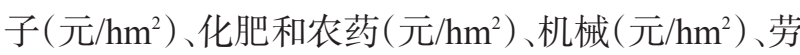
动力 $\left(\right.$ 人. 天 $\left./ \mathrm{hm}^{2}\right)$ 以及灌溉用水量 $\left(\mathrm{m}^{3} / \mathrm{hm}^{2}\right)$ 等。具 体变量描述见表 2 。

本文中提到的 “节水灌溉技术” 是包括了井灌 区的低压管道输水小畦灌和一些水库的管道输水 以及河渠引水地面灌溉等, 同时也包含喷灌和微 灌。从表 2 中数据统计情况来看, 小农户平均每公 顷种子投人为 834.0 元; 化肥和农药主要包括了尿 素、复合肥、除草剂、杀虫剂等, 合计投人均值为 3259.5 元, 其中最大投人为 5220.0 元, 最低值为 1800.0 元, 可见投人差值较大。根据调研可知, 小农 户在购买力上没有价格优势, 且抗风险能力较差, 遇上灾害时的防控力较弱,在农药和化肥的使用上 控制不足, 导致了投人差距较大。其他 3 类主体的 种子投人、化肥和农药投人的均值与小农户相比较 低, 且组间差异较小, 这是由于种粮大户、家庭农场 及农民专业合作社存在规模合作经营的优势,在购

\begin{tabular}{|c|c|c|c|c|c|c|c|}
\hline $\begin{array}{l}\text { 经营 } \\
\text { 主体 }\end{array}$ & 变量 & $\begin{array}{c}\text { 种子/ } \\
\left(\text { 元 } / \mathrm{hm}^{2}\right)\end{array}$ & $\begin{array}{c}\text { 化肥和农药/ } \\
\left(\text { 元 } / \mathrm{hm}^{2}\right)\end{array}$ & $\begin{array}{c}\text { 机械/ } \\
\left(\text { 元 } / \mathrm{hm}^{2}\right)\end{array}$ & $\begin{array}{c}\text { 劳动力/ } \\
\left(\text { 人·天 } / \mathrm{hm}^{2}\right)\end{array}$ & $\begin{array}{l}\text { 灌溉量/ } \\
\left(\mathrm{m}^{3} / \mathrm{hm}^{2}\right)\end{array}$ & $\begin{array}{c}\text { 产出/ } \\
\left(\mathrm{kg} / \mathrm{hm}^{2}\right)\end{array}$ \\
\hline \multirow[t]{3}{*}{ 小农户 } & 均值 & 834.0 & 3259.5 & 2122.5 & 34.5 & 2944.5 & 6055.5 \\
\hline & 最大值 & 1290.0 & 5220.0 & 5250.0 & 120.0 & 5190.0 & 8250.0 \\
\hline & 最小值 & 360.0 & 1800.0 & 1125.0 & 15.0 & 1350.0 & 3750.0 \\
\hline \multirow[t]{3}{*}{ 种粮大户 } & 均值 & 753.0 & 2161.5 & 1143.0 & 28.5 & 2782.5 & 7858.5 \\
\hline & 最大值 & 900.0 & 2625.0 & 1425.0 & 45.0 & 3075.0 & 9375.0 \\
\hline & 最小值 & 600.0 & 1425.0 & 825.0 & 15.0 & 2400.0 & 6450.0 \\
\hline \multirow[t]{3}{*}{ 家庭农场 } & 均值 & 751.5 & 1903.5 & 1195.5 & 43.5 & 2901.0 & 7423.5 \\
\hline & 最大值 & 825.0 & 2475.0 & 1425.0 & 75.0 & 3150.0 & 8625.0 \\
\hline & 最小值 & 675.0 & 1350.0 & 975.0 & 15.0 & 2325.0 & 6750.0 \\
\hline \multirow{3}{*}{$\begin{array}{l}\text { 农民专业 } \\
\text { 合作社 }\end{array}$} & 均值 & 673.5 & 2179.5 & 1128.0 & 26.4 & 2739.0 & 7527.0 \\
\hline & 最大值 & 825.0 & 2475.0 & 1350.0 & 60.0 & 3300.0 & 9000.0 \\
\hline & 最小值 & 525.0 & 1875.0 & 900.0 & 15.0 & 2640.0 & 6375.0 \\
\hline
\end{tabular}

表 2 主要变量的描述性统计

Table 2 Descriptive statistics of the main variables 
买种子上存在价格优惠, 且可以获得农药和化肥的 补贴。调研发现, 多地还存在鼓励政策, 化肥和农 药使用量越少则越可获得相应奖励, 新型农业经营 主体在生产条件上更加优越, 对化肥和农药的把控 也较为专业, 降低了成本, 提高了产量。机械投人 主要包括播种、收割等费用,小农户每公顷投人均 值为 2122.5 元, 最大值达到 5250.0 元, 而新型农业 经营主体的机械投人均值较低,为 1155.5 元。小农 户通常需要租用大户或机构的收割机,费用不菲, 而新型农业经营主体有一定的经济基础购买机器, 根据使用寿命平均折损下来其成本要小于小农 户。劳动力投人方面, 小农户的投人均值为 34.5 人.天 $/ \mathrm{hm}^{2}$, 新型农业经营主体的投人均值为 32.8 人・天 $/ \mathrm{hm}^{2}$ 。灌溉用水量是根据小麦生产过程中农 户的总灌溉次数及每次灌溉量而定, 小农户灌溉量 均值略高于新型农业经营主体。新型农业经营主 体的平均产量高于小农户, 3 类新型农业经营主体 产量相差不大, 表明新型农业经营主体的生产情况 较为稳定。

2.3.2 灌溉用水效率影响变量的选取与描述性分析 由于各地区自然气候和农业生产条件存在差
异,影响农业灌溉用水效率的因素也较为复杂。本 文的农业灌溉用水效率是基于生产技术效率来测 算的,且样本数据均来自于黄淮海平原冬小麦生产 区,因此在影响因素的选择上,忽略了自然气候条 件对小麦需水量的影响,而从农户灌溉管理角度来 考察可能影响效率的因素。本文参考许朗 ${ }^{[25]}$ 、耿献 辉 ${ }^{[26]}$ 等研究成果, 结合农户实际生产情况,从农户的 个人特征、家庭情况、灌溉特征 3 个方面来考虑, 具 体可表现为农户的年龄、受教育程度、是否为村干 部、是否受过培训、劳动力投人、农业收人占比、灌 溉面积、用水成本、灌溉设施、是否采用节水灌溉技 术等(表3)。

根据表 3 可知, 小农户的平均年龄为 56.09 岁, 远超过新型农业经营主体 47.31 48.87岁的年龄均 值。受教育年限平均值为 5.47 年, 远低于新型农业 经营主体 8.81 11.43 年的平均年限。这表明小农户 和新型农业经营主体相比,小农户的经营者年龄偏 大且文化教育水平偏低,身体和文化综合素质低于 新型农业经营主体的经营者。在农业生产中的劳 动力投人方面, 小农户的投人均值相对新型农业经 营主体的投人均值略高, 表明小农户仍然以密集劳

表 3 农户特征及影响因素的统计描述

Table 3 Descriptive statistics of farmers' characteristics and influencing factors

\begin{tabular}{|c|c|c|c|c|c|c|c|c|c|}
\hline \multirow{2}{*}{\multicolumn{2}{|c|}{ 变量 }} & \multicolumn{2}{|c|}{ 小农户 } & \multicolumn{2}{|c|}{ 种粮大户 } & \multicolumn{2}{|c|}{ 家庭农场 } & \multicolumn{2}{|c|}{ 农民专业合作社 } \\
\hline & & 均值 & 标准误 & 均值 & 标准误 & 均值 & 标准误 & 均值 & 标准误 \\
\hline \multicolumn{2}{|l|}{ 年龄/岁 } & 56.09 & 0.36 & 48.87 & 0.33 & 47.31 & 0.37 & 48.04 & 0.97 \\
\hline \multicolumn{2}{|l|}{ 受教育年限/年 } & 5.47 & 0.13 & 8.81 & 0.14 & 11.18 & 0.20 & 11.43 & 0.62 \\
\hline \multicolumn{2}{|c|}{ 劳动力投人/(人·天 $\left./ \mathrm{hm}^{2}\right)$} & 34.50 & 0.30 & 28.50 & 0.60 & 43.50 & 1.95 & 26.40 & 9.60 \\
\hline \multicolumn{2}{|l|}{ 灌溉面积/hm² } & 0.53 & 0.02 & 24.43 & 0.60 & 10.42 & 0.22 & 197.44 & 0.05 \\
\hline \multicolumn{2}{|l|}{ 农业收人占比/\% } & 27.00 & 3.00 & 67.00 & 1.00 & 83.00 & 1.00 & 82.00 & 76.00 \\
\hline \multirow{2}{*}{\multicolumn{2}{|c|}{ 用水成本/(元/hm²) }} & 1543.65 & 32.70 & 1404.15 & 8.85 & 1421.55 & 7.65 & 1394.25 & 11.10 \\
\hline & & \multicolumn{8}{|c|}{ 比例/\% } \\
\hline \multirow[t]{2}{*}{ 灌溉设施 } & $0=$ 河灌 & \multicolumn{2}{|c|}{70.14} & \multicolumn{2}{|c|}{33.53} & \multicolumn{2}{|c|}{48.31} & \multicolumn{2}{|c|}{21.41} \\
\hline & 1=机井灌 & \multicolumn{2}{|c|}{29.86} & \multicolumn{2}{|c|}{66.47} & \multicolumn{2}{|c|}{51.69} & \multicolumn{2}{|c|}{78.69} \\
\hline 是否采用灌溉技术 & $1=$ 是 & \multicolumn{2}{|c|}{41.23} & \multicolumn{2}{|c|}{81.44} & \multicolumn{2}{|c|}{74.58} & \multicolumn{2}{|c|}{91.48} \\
\hline \multirow[t]{2}{*}{ 是否受过培训 } & $0=$ 否 & \multicolumn{2}{|c|}{88.63} & \multicolumn{2}{|c|}{61.08} & \multicolumn{2}{|c|}{$44 . .07$} & & \\
\hline & $1=$ 是 & & & 38 & & & & & \\
\hline 是否为村干部 & $0=$ 否 & & & 83 & & & & & \\
\hline & $1=$ 是 & & & 16 & & & & & \\
\hline 水资源紧缺程度 & $0=$ 不紧缺 & & & 58 & & & & & \\
\hline & 1=紧缺 & & & 33 & & & & & \\
\hline & 2=非常紧缺 & & & & 79 & & & & \\
\hline
\end{tabular}


动开展农业生产。在灌溉面积方面, 小农户的灌溉 面积均值远远低于新型农业经营主体的灌溉面积 均值, 但是小农户的用水成本略高于新型农业经营 主体, 这表明小农户相比新型农业经营主体在单位 灌溉面积投人了更多的灌溉用水量。在是否采用 灌溉技术和是否受过培训方面, 小农户的技术采用 和参与培训的比例显著低于新型农业经营主体, 这 些变量值侧面表明小农户在节水技术采用和参与 培训程度方面低于新型农业经营主体。

\section{3 结果与分析}

\section{1 小农户与新型农业经营主体的灌溉用水效率与 技术效率分析}

本文利用Frontier 软件对小农户、种粮大户、家 庭农场、农民专业合作社分别进行农业灌溉用水效 率测算, 同时对小农户和各个新型农业经营主体的 生产技术效率进行测算,两者结合分析农业经营主 体的农业灌溉用水效率状况以及用水效率的提高 潜力。表 4 和表 5 分别是各个农业经营主体的农业 灌溉用水效率和技术效率。根据农业灌溉用水效 率公式 (6) 可知农业灌溉用水效率值和技术效率值 之间的量化关系。

从农业灌溉用水效率测算结果来看, 效率值的 分布比较分散, 波动性强。对于小农户而言, 每个 阶段的效率值都有占比, 而其他主体效率值基本分
布在 $40 \%$ 以上。从表 4 中可以看出, 小农户的农业 灌溉用水效率均值为 $40.07 \%$ 。农业灌溉用水效率 值在 $10 \%$ 50\%水平的农户占了近 70\%的比例, 最小 值仅为 $4.16 \%$, 这主要是因为个别土地的平整度较 差和土质渗水性强等原因造成的, 最大值为 $88.20 \%$, 表明小农户群体中的灌溉用水浪费现象非 常严重, 节水潜力巨大, 且效率值差异大, 变异性 强。种粮大户的农业灌溉用水效率均值为 $72.90 \%$, 效率值相对集中在 $50 \%$ 90\% 的水平,效率值达到 $60 \%$ 以上的农户超 7 成, 样本中最大值为 $99.99 \%$, 最 小值为 $43.79 \%$, 效率差值为 $56.50 \%$, 小于小农户样 本。家庭农场的农业灌溉用水效率均值为 $78.31 \%$, 效率值均在 $60 \%$ 以上水平, 达到 $80 \%$ $100 \%$ 水平的 农户超 4 成, 最大值为 $95.96 \%$, 最小值为 $60.45 \%$, 效 率差值为 $35.51 \%$, 小于种粮大户。农民专业合作社 的农业灌溉用水效率均值为 $79.54 \%$, 效率值在 50\% $\sim 60 \%$ 水平的比例只有 $1.55 \%$, 其余均在 $60 \%$ 以上水 平, 且分布较为平均, 效率值大于 $90 \%$ 水平的农户 比例为 $21.71 \%$, 较其他 3 类主体最高, 效率差值为 $40.73 \%$, 高于家庭农场而小于种粮大户。总体上 看,在小农户、种粮大户、家庭农场、农民专业合作 社这 4 类样本中,农业灌溉用水效率值的集中分布 呈现由低到高的趋势, 可以明显地看出, 家庭农场 和农民专业合作社样本中农户的农业灌溉用水效

表4 不同主体灌溉用水效率频数分布表

Table 4 Frequency distribution of irrigation water use efficiency of different types of farmers

\begin{tabular}{|c|c|c|c|c|c|c|c|c|}
\hline \multirow{2}{*}{ 效率/\% } & \multicolumn{2}{|c|}{ 小农户 } & \multicolumn{2}{|c|}{ 种粮大户 } & \multicolumn{2}{|c|}{ 家庭农场 } & \multicolumn{2}{|c|}{ 农民专业合作社 } \\
\hline & 份额/\% & 累计份额/\% & 份额/\% & 累计份额/\% & 份额/\% & 累计份额/\% & 份额 $/ \%$ & 累计份额 $/ \%$ \\
\hline $0 \sim 10$ (含) & 2.37 & 2.37 & 0.00 & 0.00 & 0.00 & 0.00 & 0.00 & 0.00 \\
\hline 10 20(含) & 15.64 & 18.01 & 0.00 & 0.00 & 0.00 & 0.00 & 0.00 & 0.00 \\
\hline 20 30(含) & 22.27 & 40.28 & 0.00 & 0.00 & 0.00 & 0.00 & 0.00 & 0.00 \\
\hline 30 40(含) & 14.22 & 54.50 & 0.00 & 0.00 & 0.00 & 0.00 & 0.00 & 0.00 \\
\hline 40 50(含) & 15.17 & 69.67 & 3.59 & 3.59 & 0.00 & 0.00 & 0.00 & 0.00 \\
\hline 50 60(含) & 10.43 & 80.09 & 19.16 & 22.75 & 0.00 & 0.00 & 1.55 & 1.55 \\
\hline 60 70(含) & 9.48 & 89.57 & 20.96 & 43.71 & 23.73 & 23.73 & 25.58 & 27.13 \\
\hline 70 80(含) & 6.64 & 96.21 & 22.75 & 66.47 & 34.75 & 58.47 & 21.71 & 48.84 \\
\hline 80 90(含) & 3.79 & 100.00 & 17.37 & 83.83 & 29.66 & 88.14 & 29.46 & 78.29 \\
\hline 90 100(含) & 0.00 & 100.00 & 16.17 & 100.00 & 11.86 & 100.00 & 21.71 & 100.00 \\
\hline 均值 & \multicolumn{2}{|c|}{40.07} & \multicolumn{2}{|c|}{72.90} & \multicolumn{2}{|c|}{78.31} & \multicolumn{2}{|c|}{79.54} \\
\hline 最大值 & \multicolumn{2}{|r|}{88.20} & \multicolumn{2}{|c|}{99.99} & \multicolumn{2}{|c|}{95.96} & \multicolumn{2}{|c|}{99.96} \\
\hline 最小值 & \multicolumn{2}{|r|}{4.16} & \multicolumn{2}{|c|}{43.79} & \multicolumn{2}{|c|}{60.45} & \multicolumn{2}{|c|}{59.23} \\
\hline
\end{tabular}


表 5 不同主体技术效率频数分布表

Table 5 Frequency distribution of technical efficiency of different types of farmers

\begin{tabular}{|c|c|c|c|c|c|c|c|c|}
\hline \multirow{2}{*}{ 效率/\% } & \multicolumn{2}{|c|}{ 小农户 } & \multicolumn{2}{|c|}{ 种粮大户 } & \multicolumn{2}{|c|}{ 家庭农场 } & \multicolumn{2}{|c|}{ 农民专业合作社 } \\
\hline & 份额/\% & 累计份额/\% & 份额/\% & 累计份额/\% & 份额/\% & 累计份额/\% & 份额/\% & 累计份额 $/ \%$ \\
\hline 0 10（含） & 0.00 & 0.00 & 0.00 & 0.00 & 0.00 & 0.00 & 0.00 & 0.00 \\
\hline 10 20(含) & 0.00 & 0.00 & 0.00 & 0.00 & 0.00 & 0.00 & 0.00 & 0.00 \\
\hline 20 30 (含) & 0.00 & 0.00 & 0.00 & 0.00 & 0.00 & 0.00 & 0.00 & 0.00 \\
\hline 30 40(含) & 0.00 & 0.00 & 0.00 & 0.00 & 0.00 & 0.00 & 0.00 & 0.00 \\
\hline 40 50(含) & 0.00 & 0.00 & 0.00 & 0.00 & 0.00 & 0.00 & 0.00 & 0.00 \\
\hline 50 60 (含) & 0.95 & 0.00 & 0.00 & 0.00 & 0.00 & 0.00 & 0.00 & 0.00 \\
\hline 60 70(含) & 4.74 & 0.00 & 0.00 & 0.00 & 0.00 & 0.00 & 0.00 & 0.00 \\
\hline 70 80(含) & 30.33 & 36.02 & 28.14 & 30.54 & 16.10 & 16.10 & 22.48 & 22.48 \\
\hline 80 90(含) & 38.39 & 74.41 & 37.72 & 68.26 & 50.85 & 66.95 & 34.11 & 56.59 \\
\hline 90 100(含) & 25.59 & 100.00 & 31.74 & 100.00 & 33.05 & 100.00 & 43.41 & 100.00 \\
\hline 均值 & \multicolumn{2}{|c|}{83.51} & \multicolumn{2}{|c|}{84.99} & \multicolumn{2}{|c|}{86.65} & \multicolumn{2}{|c|}{87.41} \\
\hline 最大值 & \multicolumn{2}{|c|}{97.85} & \multicolumn{2}{|c|}{99.99} & \multicolumn{2}{|c|}{97.64} & \multicolumn{2}{|c|}{99.98} \\
\hline 最小值 & \multicolumn{2}{|c|}{57.68} & \multicolumn{2}{|c|}{66.25} & \multicolumn{2}{|c|}{74.70} & \multicolumn{2}{|c|}{73.94} \\
\hline
\end{tabular}

率值多集中在 $70 \%$ 以上的水平, 而小农户集中在 10\% 30\%的水平, 表明小农户在农业灌溉用水效率 方面存在较大差异。小型农田灌溉水利设施不足 和灌溉技术应用程度低以及农户传统的灌溉习惯， 导致小农户的农业灌溉用水效率整体偏低,农业用 水浪费现象严重,波动性强; 而种粮大户、家庭农场 和农民专业合作社在技术和灌溉条件方面都优于 小农户,因此其农业灌溉用水效率分布多集中在较 高的水平上。

从技术效率测算结果来看,各个农业经营主体 的技术效率都达到了 $80 \%$ 以上,但都未达到技术充 分有效。在当前农机的推广和服务下,生产技术的 获取也较一致, 所以测算出的生产技术效率水平相 对来说比较集中。小农户的生产技术效率均值为 $83.51 \%$, 从频数分布情况看, 约 $40 \%$ 的农户的技术 效率低于群体均值, 效率值在 $90 \%$ 以上的占了 $25.59 \%$, 样本效率差值为 $40.17 \%$, 表明小农户群体 中, 技术效率差异比较明显。种粮大户的生产技术 效率均值为 $84.99 \%$,约 $32.00 \%$ 的样本的技术效率低 于样本均值, 效率值在 $90 \%$ 以上的占了 $31.74 \%$, 样 本效率差值为 $33.74 \%$ 。家庭农场的生产技术效率 均值为 $86.65 \%$, 约 $20 \%$ 的样本的技术效率低于样本 均值, 效率值在 $90 \%$ 以上的占了 $33.05 \%$, 样本效率 差值为 $22.94 \%$ 。农民专业合作社的生产技术效率
均值为 $87.41 \%$, 约 $25.00 \%$ 的样本的技术效率低于样 本均值, 效率值在 $90 \%$ 以上的占了 $43.41 \%$, 样本效 率差值为 $26.04 \%$ 。这可以看出, 小农户、种粮大户、 家庭农场、农民专业合作社技术效率值高于 $90 \%$ 的 比例在不断升高, 农民专业合作社的比例最高, 种 粮大户和家庭农场的比例相似,小农户最小。小农 户样本效率差值也普遍高于其他农业经营主体, 表 明相对于小农户而言,其他农业经营主体在技术应 用和其他生产条件上都较为均质,家庭农场和农民 专业合作社的技术效率分布明显要优于其他主体, 这可能是由于农民专业合作社和家庭农场样本农 户的知识和技术水平都较为丰富,专业化程度较 高,在整个农业生产上发挥了优势。结合灌溉用水 效率值可知, 小农户和新型农业经营主体的农业 灌溉用水效率均有一定的提高空间, 相对小农户 而言, 新型农业经营主体的技术应用状况相对较 好, 灌溉用水效率相对较高。小农户应该成为促 进节水灌溉技术应用、提高灌溉用水效率的主要 对象。

\section{2 小农户与新型农业经营主体的农业灌溉用水效 率影响因素分析}

本文利用计量经济学软件对 4 类农业经营主体 的样本数据, 分组进行了 Tobit模型回归。模型回归 估计结果如表 6 所示。从具体回归结果来看,不同 
表 6 Tobit 模型回归的估计结果

Table 6 Estimation results of Tobit model regression

\begin{tabular}{|c|c|c|c|c|c|c|c|c|}
\hline \multirow{2}{*}{ 变量 } & \multicolumn{2}{|c|}{ 小农户 } & \multicolumn{2}{|c|}{ 种粮大户 } & \multicolumn{2}{|c|}{ 家庭农场 } & \multicolumn{2}{|c|}{ 农民专业合作社 } \\
\hline & coefficient & $t$ & coefficient & $t$ & coefficient & $t$ & coefficient & $t$ \\
\hline 年龄 & 0.0004 & 0.50 & $0.0067 * * *$ & 6.67 & $0.0037 * * *$ & 4.89 & -0.0006 & -1.59 \\
\hline 受教育年限 & $0.0328 * * *$ & 9.73 & $0.0063^{* * *}$ & 4.15 & 0.0137 & 0.75 & $0.0163^{* * *}$ & 6.81 \\
\hline 劳动力投人 & $0.1871 * * *$ & 9.39 & 0.0030 & 0.96 & $0.0147 * * *$ & 6.34 & $0.0293 * * *$ & 2.71 \\
\hline 灌溉面积 & -0.0900 & -0.30 & $0.1350 * * *$ & 13.68 & $0.0450 * * *$ & 3.71 & 0.0675 & 0.41 \\
\hline 农业收人占比 & $0.1918 * * *$ & 11.38 & $0.1614 * * *$ & 5.94 & $0.1901 * * *$ & 6.24 & $0.0955 * * *$ & 2.53 \\
\hline 用水成本 & $0.0005 * * *$ & 3.95 & $0.0024 * * *$ & 6.74 & $0.0007 * *$ & 2.29 & $0.0002 * * *$ & 3.14 \\
\hline 灌溉设施 & -0.0102 & -1.16 & $0.0106 * * *$ & 2.66 & $0.0081 * *$ & 2.75 & $0.0364 * * *$ & 4.21 \\
\hline 是否采用灌溉技术 & $0.0255^{* *}$ & 2.30 & $0.0124 * *$ & 2.66 & $0.0045^{*}$ & 1.78 & $0.0688 * * *$ & 6.38 \\
\hline 是否受过培训 & 0.0021 & 0.10 & $0.0178 * *$ & 3.73 & 0.0032 & 1.29 & $0.0136^{* *}$ & 2.29 \\
\hline \multicolumn{9}{|l|}{ 水资源紧缺程度 } \\
\hline 1 & 0.0005 & 0.06 & -0.0023 & -0.49 & -0.0007 & 0.20 & $0.0359 * * *$ & 5.14 \\
\hline 2 & -0.0038 & -0.28 & $0.0205 * *$ & 2.43 & $0.0145^{* *}$ & 2.91 & $0.0205^{*}$ & 1.78 \\
\hline
\end{tabular}

注: $* * * * *$ 、*分别代表在 $1 \% 、 5 \% 、 10 \%$ 的水平上显著。

农业经营主体的回归结果有所区别。从每个群体 回归得到的似然估计值可以看出,模型整体拟合较 好, Tobit模型设定适用于影响因素的分析,在 4 类 经营主体中,小农户群体有较多因素没有通过显著 性检验,其余 3 类的大多数影响因素基本都通过了 检验,其具体区别总结如下:

\subsection{1 小农户}

根据模型回归估计结果可知, 受教育年限、劳 动力投人、农业收人占比、用水成本及是否采用灌 溉技术这 5 项因素对小农户的农业灌溉用水效率产 生了正向影响,并通过了显著性检验。受教育年限 越长可以增加农户的知识水平和综合素质, 有助于 提高农业灌溉用水效率, 因此受教育程度对农业灌 溉用水效率具有正向影响。小农户由于户主年龄 偏大, 且机械化程度低, 需要更多的劳动力帮助耕 地灌溉, 因此劳动力对于小农户来说对农业灌溉用 水效率具有正向影响。农业收人占比越高表明农 业是其家庭获取收人的主要来源, 劳动积极性也越 高, 越有利于提高农业灌溉用水效率。用水成本作 为农业生产中的另一笔支出对于小农户来说也非 常重要,会约束农户的浪费行为, 提高农业灌溉用 水效率。灌溉技术在灌溉用水管理中起着非常重 要的作用。根据模型回归估计结果可知, 灌溉技术 的推广和应用对于小农户、种粮大户、家庭农场和
农民专业合作社的农业灌溉用水效率都有显著的 促进作用。

剩余几个因素没有通过显著性检验, 小农户的 劳动主力的年龄偏大,耕地面积小且较为分散,农 户使用水源的渠道较多, 局限于自身的灌溉条件和 资源整合能力,农户年龄、灌溉面积和灌溉设施变 量对农业灌溉用水效率的影响在小农户群体中不 显著。农户是否受过培训和是否为村干部这两项 因素都没有显示出对农业灌溉用水效率有显著影 响, 仍然是由于小农户的劳动主体多为留守老人, 其对知识的接受程度和意愿都很低造成的。村干 部的担任人也并不是依托农业种植经验, 因此并没 有直接影响到农户的灌溉用水效率。从回归结果 来看, 小农户样本中部分影响因素没有通过显著性 检验,一是调研数据不够大, 且小农户地块较为分 散, 易受到地理区域的影响;二是由于小农户灌溉 规模相对较小, 灌溉用水的总投人也相对较小, 以 至于很多影响灌溉用水投人的因素变化时给灌溉 用水投人带来的变化,并不能有效的促进小农户的 灌溉用水节约意识。因此,这些影响因素对小农户 的灌溉行为未表现出显著的影响。

\subsection{2 种粮大户}

种粮大户作为新型的农业经营主体, 在农业生 产和灌溉用水方面有更多优势。在影响因素的分 
析中发现, 年龄、教育年限、灌溉面积、用水成本、灌 溉设施、是否采用灌溉技术、是否受过培训、水资源 紧缺程度均对农业灌溉用水效率有正向影响。种 粮大户承包的土地规模较大, 需要其拥有丰富的耕 地经验和管理能力, 年龄上不会太大, 一定程度上 可以对农业灌溉用水效率产生正向影响,农户的文 化程度对种粮大户来说也在农业生产上起到了促 进作用。种粮大户耕地面积较大,存在规模化经 营, 具有统一的灌溉条件,有利于减少水资源浪费 现象,耕地面积的增加在一定程度上可以提高农业 灌溉用水效率。用水成本对于实现规模化经营的 种粮大户会起到约束用水行为的作用, 为了控制用 水成本, 在对灌溉技术的使用和管理上更加重视， 有利于提高农业灌溉用水效率。在灌溉设施上, 回 归结果通过了显著性检验, 表明与河灌相比, 机井 灌的灌溉用水效率更高, 对水资源的使用比较谨 慎。节水灌溉技术在新型农业经营主体的农业灌 溉中发挥了重要作用, 区别于小农户, 新型农业经 营主体具有更好的土地条件和较多的资金, 便于节 水灌溉技术的推广和使用。对于种粮大户而言, 只 有当水资源非常紧缺时才会促进农业灌溉用水效 率的提高。种粮大户的劳动力投人因素没有通过 显著性检验, 可能的解释是种粮大户大多实现机械 化运作, 且在调研中发现大户的人力雇佣成本较 高, 机械化的使用可以降低人力成本, 增加收人, 这 可能是其不显著的原因。

\subsection{3 家庭农场}

家庭农场较之种粮大户在生产经营上有自身 特点。模型的回归结果中发现, 年龄、劳动力投人、 灌溉面积、农业收人占比、用水成本、灌溉设施、是 否采用灌溉技术和水资源紧缺程度均对农业灌溉 用水效率有正向影响, 但受教育年限、是否受过培 训和是否为村干部这 3 个影响因素没有通过显著性 检验。通过调研发现产生这种状况的主要原因是 家庭农场的农场主通常是由家庭成员中的父亲或 母亲来担任, 但是由于儿子或女儿的受教育程度通 常更高, 儿子或女儿在农场经营过程中是实际的决 策者和管理者。本文中家庭农场的调研对象主要 是农场主, 从而隐蔽了家庭农场样本中受教育年限 因素对农业灌溉用水效率的真实影响。鉴于相同
的原因,农场主是否受过培训这一因素对农业灌溉 用水效率的影响也不显著。

\subsection{4 农民专业合作社}

农民专业合作社样本组中,农业灌溉用水效率 的影响因素模型回归结果显示, 受教育年限、劳动 力投人、农业收人占比、灌溉设施、是否采用灌溉技 术、是否受过培训、水资源紧缺程度均对农业灌溉 用水效率有正向影响。农民专业合作社是一个合 作组织, 其带头人一般为经验较为丰富或受教育程 度较高的管理者,因此年龄上并没有一个明显的规 律, 对农业灌溉用水效率影响较小, 这是其不显著 的原因。并且由于其自身组织的性质,有多家农户 联合经营,耕地面积很大,在管理上存在一定的困 难, 面积过大意味着面临的自然风险也随之增大, 因此这一因素也不显著。与其他两类新型农业主 体不同的是, 农民专业合作社的水资源紧缺意识很 强, 在认为紧缺和非常紧缺的情况下都显著影响了 其农业灌溉用水效率。

\section{4 结论与政策建议}

\section{1 结论}

本文主要研究了不同农业经营主体的农业灌 溉用水效率以及差异, 并进一步分析了农业灌溉用 水效率的影响因素。通过对技术效率和农业灌溉 用水效率的结合分析,研究发现:

（1）小农户、种粮大户、家庭农场、农民专业合 作社样本中,农业灌溉用水效率值的集中分布呈现 由低到高的趋势。家庭农场和农民专业合作社样 本中的农业灌溉用水效率值多集中在 $70 \%$ 以上的 水平,而小农户集中在 $10 \%$ 30\%的水平,表明小农 户在农业灌溉用水效率方面存在较大差异。结合 各个农业经营主体的生产技术效率可知,小农户和 新型农业经营主体的农业灌溉用水效率均有一定 的提高空间，小农户应该成为促进节水灌溉技术应 用、提高灌溉用水效率的重要对象。

(2)在农业灌溉用水效率的影响因素上,本文 利用受限变量 Tobit模型对不同农业经营主体农业 灌溉用水效率的影响因素分别作出了回归分析, 从 农户的个人特征、家庭情况、灌溉特征 3 个方面来考 虑, 结果发现不同农业经营主体影响其农业灌溉用 水效率的因素也有所区别,基于各个农业经营主体 
的自身经营特征,表现出不同的效应。农户年龄、 灌溉面积、灌溉设施等因素对于小农户的农业灌溉 用水效率无显著影响, 而对新型农业经营主体有显 著的正向影响。这表明未来在进行农业灌溉用水 效率的研究中, 应重点区别各个农业经营主体的灌 溉特征和用水行为, 从而有针对性的进行政策扶持 用水管理。

\section{2 政策建议}

针对以上研究结果,本文提出相关建议:

(1)加快新型主体发展, 发挥规模化、专业化经 营优势, 进一步加快传统农户向新型农业主体转 型, 发挥新型主体在规模经营、资源利用以及资金 支持方面的优势。传统小农经济已无法适应现代 化农业发展, 为确保在提高农业生产力的同时减少 水资源浪费, 提高灌溉用水效率, 改善用水矛盾, 政 府需要从政策上给予新型农业主体发展的平台和 补贴激励, 鼓励小农户通过土地流转或加人农民专 业合作社等形式进行规模化和专业化生产。从研 究结果可以看出, 新型农业经营主体的灌溉用水效 率的分布更加集中也更加高效, 这得益于新型农业 经营主体的专业化管理和规模化经营, 规模化和专 业化的经营模式将更有利于土地资源整合和灌溉 技术的采用, 同时也可节约生产成本, 推广机械化 服务, 建设统一的水利灌溉设施。摒弃传统散户小 户由于资金限制、劳动力不足、机械成本高等原因 而造成资源浪费、生产力低下、灌溉用水效率低等 问题。

(2) 因地制宜, 发展节水灌溉技术。从本文回 归结果可知, 无论是灌溉条件较为落后的传统小农 户, 还是新型农业经营主体, 节水灌溉技术在提高 农业灌溉用水效率上都发挥了重要作用。传统的 漫灌方式浪费了大量水资源, 且破旧老化的土渠已 不再适合当今农业的现代化生产。本文研究的对 象是冬小麦, 其主要采取的灌溉技术是渠道防渗技 术和低压管道等。因此,政府相关部门要大力推广 节水技术, 加大资金投人, 给予相应的灌溉节水设 施建设补贴, 促进农户使用渠道防渗技术和低压管 道等节水技术的积极性, 对于不同地区的地块类型 选取适合的节水技术, 联合农户和政府的力量, 进 行土地资源的规划管理, 规模化生产也有利于建设
统一的节水设施。依据不同主体的经营方式给予 相应的政策和资金扶持,促使新型主体在发展转型 的同时加强节水技术的使用, 提高农业灌溉用水 效率。

(3)加大公共服务建设。精准扶持灌溉设施的 建设与推行很大程度上需要政府的政策支持和管 理, 比如对于地块分布不均的地区进行土地平整, 对于土地条件较好的地区统一铺设管道,优化水利 条件。同时,应建立培训平台, 定期给予农户技术 知识的灌输, 解决农户生产中的疑难问题, 建立健 全反馈机制。通过本文研究的结果可以看出, 不同 农业经营主体的农业灌溉用水效率分布不同,影响 因素也有所区别, 其中农户是否受过培训这一因 素, 除小农户外,其他多数农业经营主体都通过了 显著性检验, 表明参加过农业培训的农户将更有利 于提高其农业灌溉用水效率。传统小农户确实与 新型农业经营主体在农业生产和农业灌溉用水效 率的问题上有较大差异, 但新型农业经营主体作为 未来农业生产中的用水大户,在发展中也存在着不 同程度问题,相关部门要根据不同主体的生产经营 特点, 精准到点, 精确到户, 对于不同主体的用水需 求和技术选择提供最合适的服务。

(4)发展农民用水协会, 完善水价机制。根据 本文的研究结论可知, 灌溉面积的扩大通常伴随着 农业灌溉用水效率的提高。农民用水协会是在不 改变小农户种植规模的基础上,通过统一组织灌溉 来加强农业用水管理的合作组织。根据已有文献 分析 , 农民用水户协会将有助于农户参与到灌溉管 理中去 ${ }^{[2]}$ 。水资源作为农业生产的公共资源, 需要 农业生产者的共同维护,而传统的小农意识和水费 机制的不完善,使得农户在用水方面存在很大随意 性,没有节约意识。在影响因素的回归结果中, 家 庭农场和农民专业合作社两个群体, 在水资源紧缺 程度的认识上要高于小农户和种粮大户,而紧缺意 识越强, 越有利于节约水资源, 提高农业灌溉用水 效率。在实地调研中发现,大部分地区用水协会的 管理和建设都没有落实到位,表明农户的灌溉管理 参与度较低, 政府等相关部门也没有宣传到位, 很 多农户都不知道村里存在用水协会, 对水资源自我 管理的认识浅薄,认为水资源是一种公共资源, 缺 
乏对农业用水的正确认知。因此,水价机制的改革 可以让水资源从公共资源变为商品,已有部分地区 实行了水价改革且颇有成效,但还需要政府部门的 严格管理和执行,确保水价改革广泛推行。

\section{参考文献(References):}

[1] 易富贤. 中国: 人口过多? 人均资源不足?[J]. 社会科学论坛, 2006, (19): 50-71. [Yi F X. China: Overpopulation? Inadequate per capital resources?[J]. Tribune of Social Sciences, 2006, (19): 50-71.]

[2] 于智媛, 梁书民. 基于 Miami 模型的西北干旱半干旱地区灌溉 用水效果评价: 以甘宁蒙为例[J]. 干旱区资源与环境, 2017, 31 (9): 49-55. [Yu Z Y, Liang S M. Analysis of irrigation water using efficiency in arid and semi-arid areas in northwest China based on Miami model[J]. Journal of Arid Land Resources and Environment, 2017, 31(9): 49-55.]

[3 ] 杨得瑞, 刘定湘. 加快水利改革发展五年回貽[J]. 水利发展研 究, 2016, 16(8): 21-27. [Yang D R, Liu D X. Review of speeding up the reform and development of water conservancy in the past five years[J]. Water Conservancy Development Research, 2016, 16 (8): 21-27.]

[4] 罗必良. 小农经营、功能转换与策略选择: 兼论小农户与现代农 业融合发展的“第三条道路” [J]. 农业经济问题, 2020, (1): 2847. [Luo B L. Small household operation, function transformation, strategy options: How can small household incorporate into the modern agricultural development pattern? [J]. Issues in Agricultural Economy, 2020, (1): 28-47.]

[5]刘畅, 吕杰. 新型农业经营体系研究: 知识图谱、理论框架构建 与未来展望[J]. 经济体制改革, 2020, (2): 74-79. [Liu C, Lv J. Research on new agricultural management system: Knowledge map, a theoretical model and future prospects[J]. Reform of Economic System, 2020, (2): 74-79.]

[6] 杨军. 新型农业经营主体的技术效率对撂荒农地再利用的影 响: 基于 2014-2018 年粤赣的调查数据[J]. 农业技术经济, 2019, (12): 34-42. [Yang J. The influence of technical efficiency of new agricultural operators on the reuse of abandoned farmland: Based on the survey data of Guangdong and Jiangxi from 2014 to 2018[J]. Journal of Agrotechnical Economics, 2019, (12): 34-42.]

[7] 周冲, 黎红梅. 新型农业经营主体参与小农水管护行为影响因 素分析: 来自安徽省 204 个样本的调查[J]. 农村经济, 2020, (4): 116-124. [Zhou C, Li H M. Analysis on the influencing factors of new agricultural operators' participation in small-scale agricultural water management and protection behavior: A survey of 204 samples from Anhui Province[J]. Rural Economy, 2020, (4): 116124.]
[8] 于伟咏, 漆雁斌, 韦锋, 等. 水旱轮作模式和灌溉方式对西南地 区水稻灌溉用水效率的影响[J]. 资源科学, 2017, 39(6): 11271136. [Yu W Y, Qi Y B, Wei F, et al. The impact of FDD rotation mode and irrigation methods on rice irrigation water efficiency in Southwestern China[J]. Resources Science, 2017, 39(6): 11271136.]

[9] 常明.农户兼业行为影响灌溉效率吗? 基于 CFPS 的微观证据 [J]. 农林经济管理学报, 2020, 19(6): 681-689. [Chang M. Can farmers' concurrent business behavior affect irrigation efficiency? A study based on microscopic evidence from CFPS[J]. Journal of Agro- Forestry Economics and Management, 2020, 19(6): 681689.]

[10］孙才志, 刘玉玉. 基于 DEA 的中国水资源利用相对效率的时空 格局分析[J]. 资源科学, 2009, 31(10): 1696-1703. [Sun C Z, Liu Y Y. Analysis of the spatial-temporal pattern of water resources utilization relative efficiency based on DEA-ESDA in China[J]. Resources Science, 2009, 31(10): 1696-1703.]

[11] 李周, 于法稳. 西部地区农业生产效率的 DEA 分析[J]. 中国农 村观察, 2005, (6): 2-10. [Li Z, Yu F W. Analysis on agricultural productive efficiency in west China: DEA method [J]. China Rural Survey, 2005, (6): 2-10.]

[12] 张玲玲, 丁雪丽, 沈荣, 等. 中国农业用水效率空间异质性及其 影响因素分析[J]. 长江流域资源与环境. 2019, 28(4): 817-828. [Zhang L L, Ding X L, Shen Y, et al. Spatial heterogeneity and influencing factors of agricultural water use efficiency in China[J]. Resources and Environment in the Yangtze River Basin, 2019, 28 (4): 817-828.]

[13] 奕健, 韩一军. 干旱灾害与农田灌溉对小麦生产技术效率的影 响[J]. 资源科学, 2019, 41(8): 1387-1399. [Luan J, Han Y J. Impacts of drought disasters and farmland irrigation on wheat production technical efficiency[J]. Resources Science, 2019, 41(8): 13871399.]

[14] 王晓娟, 李周. 灌溉用水效率及影响因素分析[J]. 中国农村经 济, 2005, (7): 11-18. [Wang X J, Li Z. Productive efficiency of irrigation water and analysis of the causal factors[J]. Chinese Rural Economy, 2005, (7): 11-18.]

[15] 王学渊, 赵连阁. 中国农业用水效率及影响因素: 基于 19972006 年省区面板数据的 SFA 分析[J]. 农业经济问题, 2008, 29 (3): 10-17. [Wang X Y, Zhao L G. Agricultural water efficiency and the causal factors: A stochastic frontier analysis based on Chinese provincial panel data: 1997-2006[J]. Issues in Agricultural Economy, 2008, 29(3): 10-17.]

[16] 王学渊. 基于数据包络分析方法的灌溉用水效率测算与分解 [J]. 农业技术经济, 2009, (6): 40-49. [Wang X Y. The irrigation water efficiency calculation and decomposition based on envelopment analysis methods[J]. Journal of Agrotechnical Economics, 
2009, (6): 40-49.]

[17] 常明, 王西琴, 贾宝珍. 中国粮食作物灌溉用水效率时空特征及 驱动因素: 以稻谷、小麦、玉米为例[J]. 资源科学. 2019, 41(11): 2032-2042. [Chang M, Wang X Q, Jia B Z. Driving factors and spatiotemporal differentiation of irrigation water use efficiency in China[J]. Resources Science, 2019, 41(11): 2032-2042.]

[18] 刘维哲, 常明, 王西琴. 基于随机前沿的灌溉用水效率及影响因 素研究: 以陕西关中地区小麦为例[J]. 中国生态农业学报. 2018, 26(9): 1407-1414. [Liu W Z, Chang M, Wang X Q. Irrigation water efficiency based on stochastic production frontier and influencing factors: An empirical study of wheat in Guanzhong Region, Shaanxi[J]. Chinese Journal of Eco-Agriculture, 2018, 26(9): 1407-1414.]

[19] Al- Jamal M S, Ball S, Sammis T W. Comparison of sprinkler, trickle and furrow irrigation efficiencies for onion production[J]. Agricultural Water Management, 2001, 46(3): 253-266.

[20] 李贵芳, 周丁扬, 石敏俊. 西北干旱区作物灌溉技术效率及影响 因素[J]. 自然资源学报, 2019, 34(4): 853-866. [Li G F, Zhou D Y, Shi M J. Technical efficiency of crop irrigation and its determinants in the arid areas of Northwest China[J]. Journal of Natural Resources, 2019, 34(4): 853-866.]

[21] 张义珍. 我国农业经营主体疆农的现状与发展趋势[J]. 新疆农 脣经济, 1998, (5): 7-9. [Zhang Y Z. Current situation and development trend of agriculture in Xinjiang, the main body of agricultural management in China[J]. Xinjiang State Farms Economy, 1998, (5): 7-9.]

[22] 陈晓华. 突出扶持重点切实增强新型农业经营主体发展带动能 力[J]. 农业经济问题, 2020, (11): 4-7. [Chen X H. Highlight the key points of support, and enhance the development driving capacity of new types of agricultural businesses[J]. Issues in Agricultural Economy, 2020, (11): 4-7.]
[23] 李宁, 汪险生, 陆华良. 新型农业经营主体农机作业服务的双重 角色及其动态转变: 一个初步的分析框架[J]. 农业经济问题, 2021, (2): 38-53. [Li N, Wang X S, Lu H L. The dual role and dynamic transformation of agricultural machinery operation service of new agricultural management subject: A preliminary analytical framework[J]. Issues in Agricultural Economy, 2021, (2): 38-53.]

[24] 朱丽娟, 张改清, 张建杰. 水土资源利用方式对种粮大户技术效 率的影响分析: 基于黑龙江省 697 个种粮大户的调查数据[J]. 经济经纬, 2018, 35(5): 66-72. [Zhu L J, Zhang G Q, Zhang J J. The Effect of water and land resources utilization methods on the technical efficiency of major producers of grain: Based on the survey data of 697 major producers of grain in Heilongjiang Province [J]. Economic Survey, 2018, 35(5): 66-72.]

[25] 许朗, 黄茑. 农业灌溉用水效率及其影响因素分析: 基于安徽省 蒙城县的实地调查 [J]. 资源科学, 2012, 34(1): 105-113. [Xu L, Huang Y. Measurement of irrigation water efficiency and analysis of influential factors: An empirical study of Mengcheng County in Anhui Province[J]. Resources Science, 2012, 34(1): 105-113.]

[26] 耿献辉, 张晓恒, 宋玉兰. 农业灌溉用水效率及其影响因素实证 分析-基于随机前沿生产函数和新疆棉农调研数据 $[J]$. 自然资 源学报, 2014, 29(6): 934-943. [Geng X H, Zhang X H, Song Y L. Measurement of irrigation water efficiency and analysis of influential factors: An empirical study based on stochastic production frontier and cotton farmers' data in Xinjiang[J]. Journal of Natural Resources, 2014, 29(6): 934-943.]

[27] 张向达, 朱帅. 基于技术效率及影子价格的农业灌溉弹性需水 研究: 以黑龙江省为例[J]. 地理科学, 2018, 38(7): 1165-1173. [Zhang X D, Zhu S. The flexible demand analysis of agricultural irrigation water use based on tech-nical efficiency and shadow price: Taking Heilongjiang Province for an example[J]. Scientia Geographica Sinica, 2018, 38(7): 1165-1173.] 


\title{
Comparison of irrigation efficiency of smallholder farmers and new agricultural operators and influencing factors
}

\author{
XU Lang, CHEN Jie, LIU Chen \\ (College of Economics and Management, Nanjing Agricultural University, Nanjing 210095, China)
}

\begin{abstract}
New agricultural operators are the main force of agricultural development in China. Based on the field investigation data of the North China Plain area, this study selected winter wheat as the research object, applied a stochastic frontier analysis (SFA) model to calculate the irrigation water use efficiency of winter wheat with different agricultural operators, and used the Tobit model to explore the factors that affect the irrigation water use efficiency of different subjects. The study found that there are great differences in irrigation water use efficiency of smallholder farmers, large grain growers, family farms, and agricultural cooperatives, and the irrigation water use efficiency values of farmers in family farms and agricultural cooperatives are mostly concentrated at the level of more than $70 \%$. On the other hand, smallholder farmer irrigation water use efficiency values are concentrated at the level of $10 \%$ to $30 \%$. Combined with the technical efficiency of various agricultural operators, we can see that the irrigation water use efficiency of smallholder farmers and new agricultural operators have a certain space to improve; significant differences exist in the factors that affect irrigation water use efficiency of smallholder farmers and new agricultural operators, such as the level of education and labor force; and the proportion of agricultural income, water cost, and adoption of advanced irrigation technology have a positive impact on the irrigation water use efficiency of all agricultural operators. Among the new agricultural operators, farmers' age, irrigation area, irrigation facilities, and training measures can improve their irrigation water use efficiency, but have no significant impact on the irrigation water use efficiency of smallholder farmers. Smallholder farmers should be an important target to promote the application of watersaving irrigation technology and improve the efficiency of irrigation water use. Measures such as speeding up the transformation of traditional farmers to a new type of agricultural operator and increasing the development of public services will help to improve the efficiency of irrigation water use.
\end{abstract}

Key words: smallholder farmers; new agricultural management entities; irrigation water use efficiency; stochastic frontier analysis (SFA); North China Plain 